\title{
CUSTOM SHAPED CAPS FOR LPG FILLING POINTS
}

\author{
POGOREVC, P.; TASIC, T. \& BRAJLIH, T.
}

Abstract: Laser-sintering represents very efficient way for manufacturing products directly from three dimensional computer-aided design files. Such productions are very fast, flexible and cost effective for individual products. This paper shows the manufacturing procedure of custom shaped caps for liquid petroleum gas filling points. With such a procedure, the customer can express their own filling cap design, which is then modelled in the appropriate software; the electronic data of the model is taken directly into the laser-sintering machine. The product is built in a cost effective manner out of white polyamide material. Custom shaped caps can also be painted into the customer desired colour afterwards.

Key words: $L P G$ conversion, custom shaped parts, $3 D$ CAD, laser-sintering
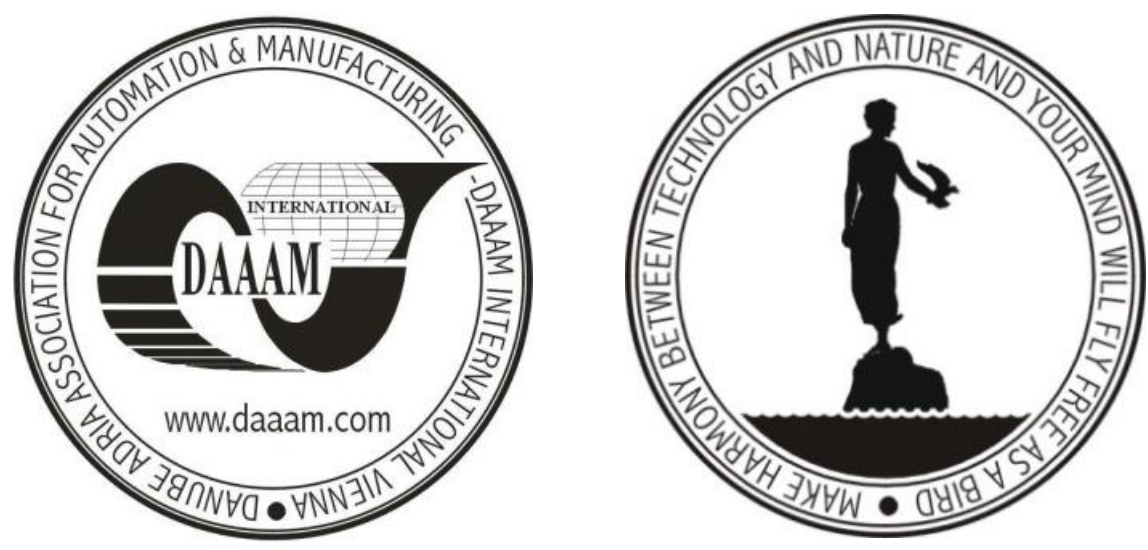

Authors' data: Dr. Sc. Pogorevc, P[rimoz]*; Dr. Sc. Tasic, T[adej]**; MSc. Brajlih, T[omaz]***, *RA-CEN d.o.o., Gozdarska cesta 55, 2382, Mislinja, Slovenia, **PLINeks d.o.o., Straže 65, 2382, Mislinja, Slovenia, ***Faculty of Mechanical Engineering, University of Maribor, Smetanova ulica 17, 2000, Maribor, Slovenia, primoz.pogorevc@razvojni-center.si, tadej.tasic@plineks.si, tomaz.brajlih@uni-mb.si

This Publication has to be referred as: Pogorevc, P[rimoz]; Tasic, T[adej] \& Brajlih, T[omaz] (2011). Custom shaped caps for LPG filling points, Chapter 42 in DAAAM International Scientific Book 2011, pp. 527-534, B. Katalinic (Ed.), Published by DAAAM International, ISBN 978-3-901509-84-1, ISSN 1726-9687, Vienna, Austria

DOI: $10.2507 /$ daaam.scibook.2011.42 


\section{Introduction}

Liquid Petroleum Gas or LPG is synthesised by refining petroleum natural gas. It is usually derived from fossil fuel sources, during the process of crude oil refining or by extraction from oil or gas streams as they emerge from the ground. As a low carbon and low polluting fossil fuel, it is recognized by governments around the world for the contribution it can make towards improved indoor and outdoor air quality and reduced greenhouse gas emissions. LPG meets all four key objectives set by the EU in its guidelines for trans-European energy networks:

- security of supply - there is sufficient amount of LPG produced in Europe and other parts of the world,

- sustainable development - LPG is a potential answer to many sustainable development challenges,

- competitiveness - the European LPG industry is highly competitive and is constantly developing new services for domestic and commercial users and

- affordability for citizens - in most parts of Europe, LPG vehicles can be significantly cheaper to run compared to petrol or diesel models.

Therefore, aftermarket LPG conversion kits are very popular in several countries. Most of the petrol engines are suitable for such conversion, which include installation of filling point, tank, reducer, injectors, ECU, change over switch, tubes and wiring. Component locations are shown in Figure 1.
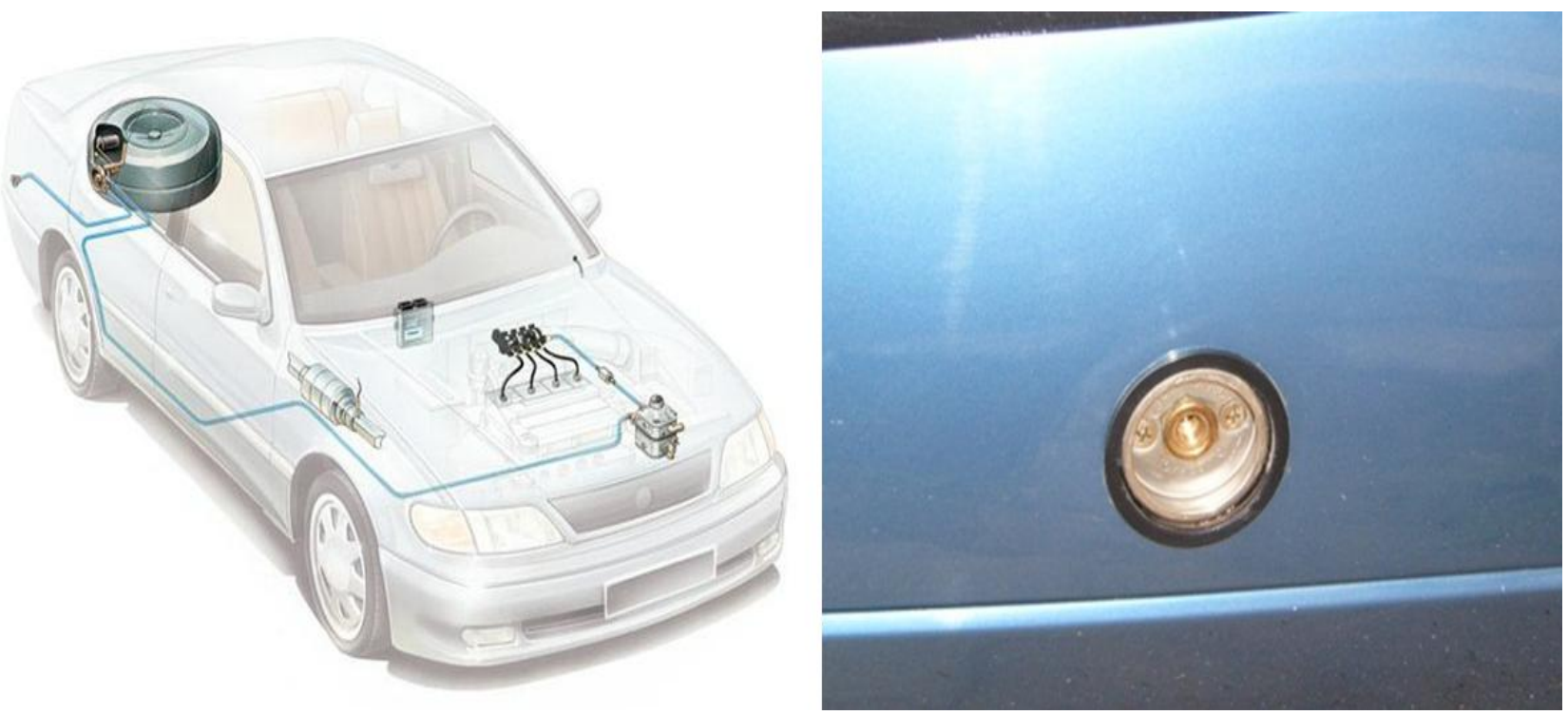

Fig. 1. LPG Conversion kit (www.landi.it) and filling point

As can be seen in Figure 1, the LPG filling point is mounted on one side of the car's rear bumper. It is specially shaped, so that filler's nozzle on the LPG filling station can be easily and firmly connected. It must be protected because of all the water and dirt coming from the rear wheel. Usually the plastic cap screwed into the 
filling point is used. In order to prevent LPG leakage, the filling point contains a check valve, so the main or even the only purpose of plastic cap is the assurance of clean filling point, each and every time you want to fill up the tank. Therefore, it does not need any special approval or homologation.

\section{Laser-sintering}

Laser-sintering is a layer manufacturing technology (Rosker, 2007). It stands for fast, flexible and cost effective production directly from three dimensional Computer-Aided Design (3D CAD) data files. Three dimensional description of the part is converted into a set of slices, which describe its cross sections in a defined height. The laser-sintering machine builds up theses slices, layer by layer, in order to create the desired object. With the help of a scanner the powder in each layer is fused together using a laser, which solidified each layer of the finished product. Part's layer is produced on top of the previous one, until the product is complete. Figure 2 illustrates the repeating process of building layers. It takes around one hour to build between 15 and $25 \mathrm{~mm}$ of the product in height. Parts built in today's polyamide material have mechanical properties comparable to injection moulded polyamide 12 or acrylonitrile butadiene styrene. The typical tensile strength ranges from 40 to 50 $\mathrm{MPa}$, with Young's modulus between 1,700 and 3,500 $\mathrm{MPa}$ with the help of appropriate fillers.

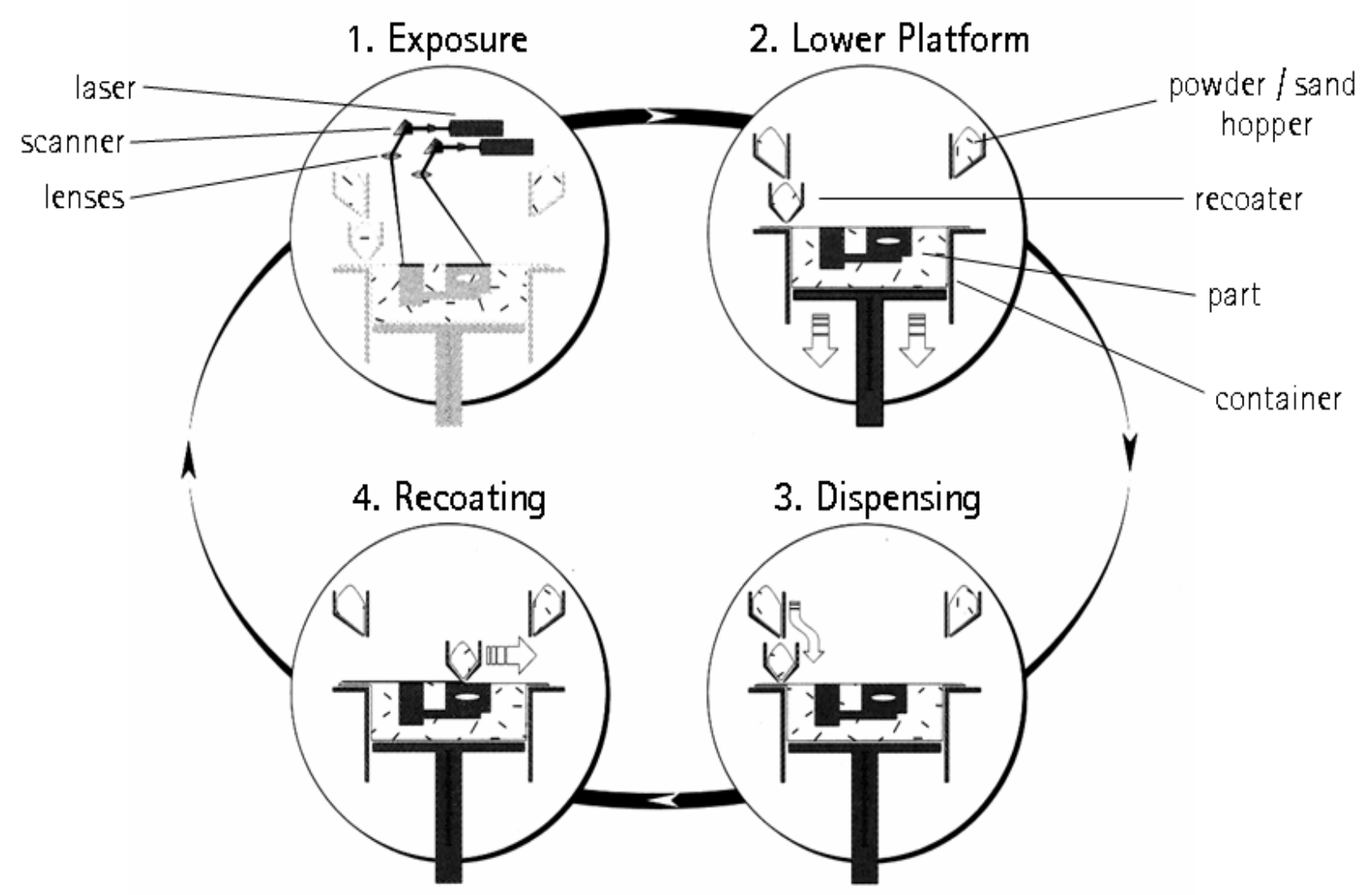

Fig. 2. Working Principle of Laser-Sintering 
Pogorevc, P.; Tasic, T. \& Brajlih, T.: Custom Shaped Caps for LPG Filling Points

\section{Custom cap manufacturing procedure}

The first step of manufacturing procedure is gathering information from car's owner, regarding the desired shape and colour of the protection cap. Based on that, 3D modelling can begin in the majority of the 3D CAD software. In order to fit inside the filling point and to insure desired protection, shape, measurements and thread on the bottom half of the cap must be the same for every peace (Figure 3).

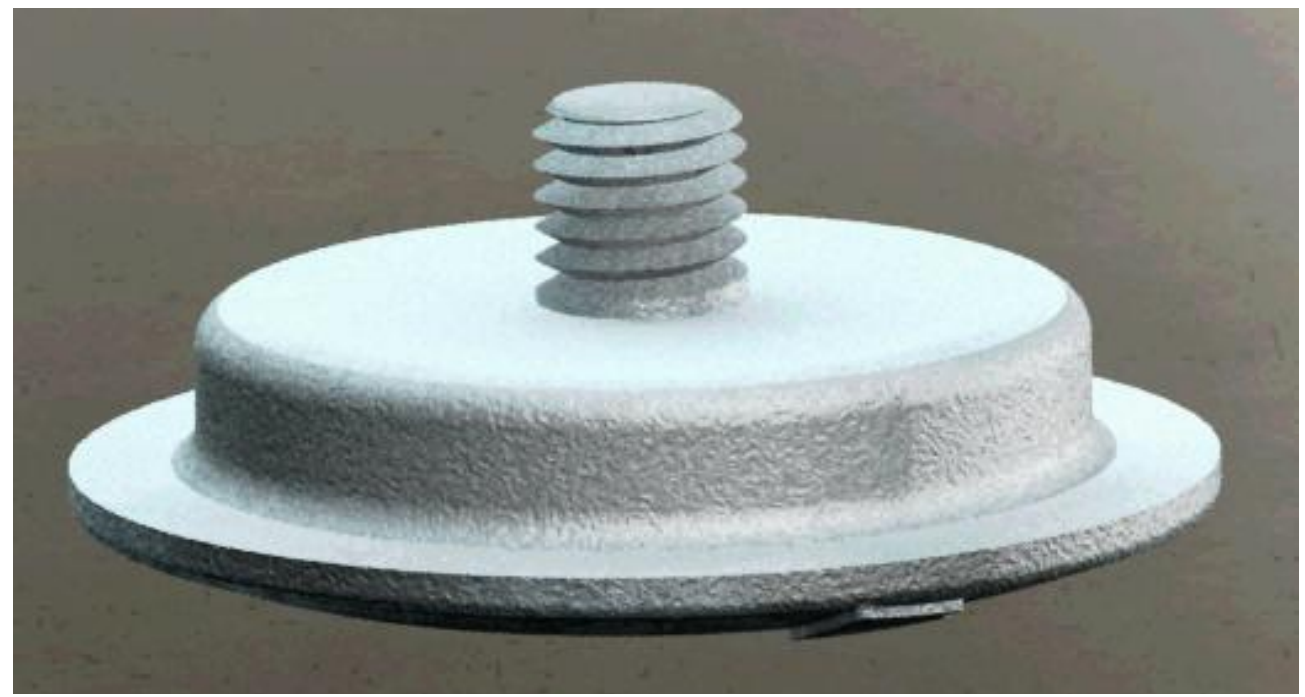

Fig. 3. Bottom side of the protection cap

The top side can be shaped accordingly to the owner wishes. During the protection cap modelling it should be considered, that you must be able to unscrew it by hand. Therefore, there must be enough room for your fingers. Two 3D models of the protection caps are presented on Figure 4.

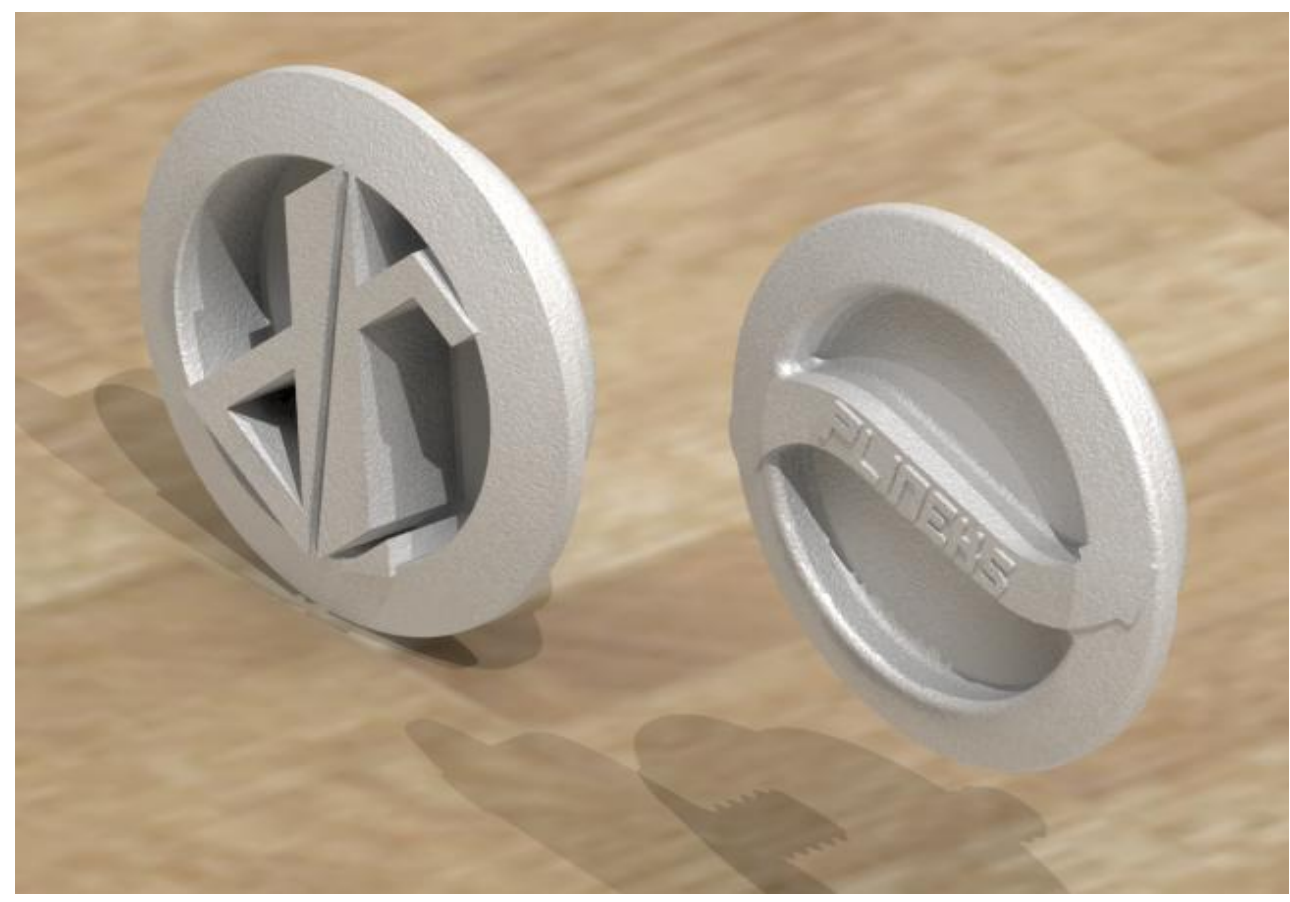

Fig. 4. 3D models of the custom protection caps 
It can be seen, that both models have the same basic shape, but overall they look completely different. There are numerous possibilities of the design. You can incorporate factory's names or logos, car brands, owners initials, acronyms,... The machine FORMIGA P 100 (figure 5) represents laser-sintering in the compact class.

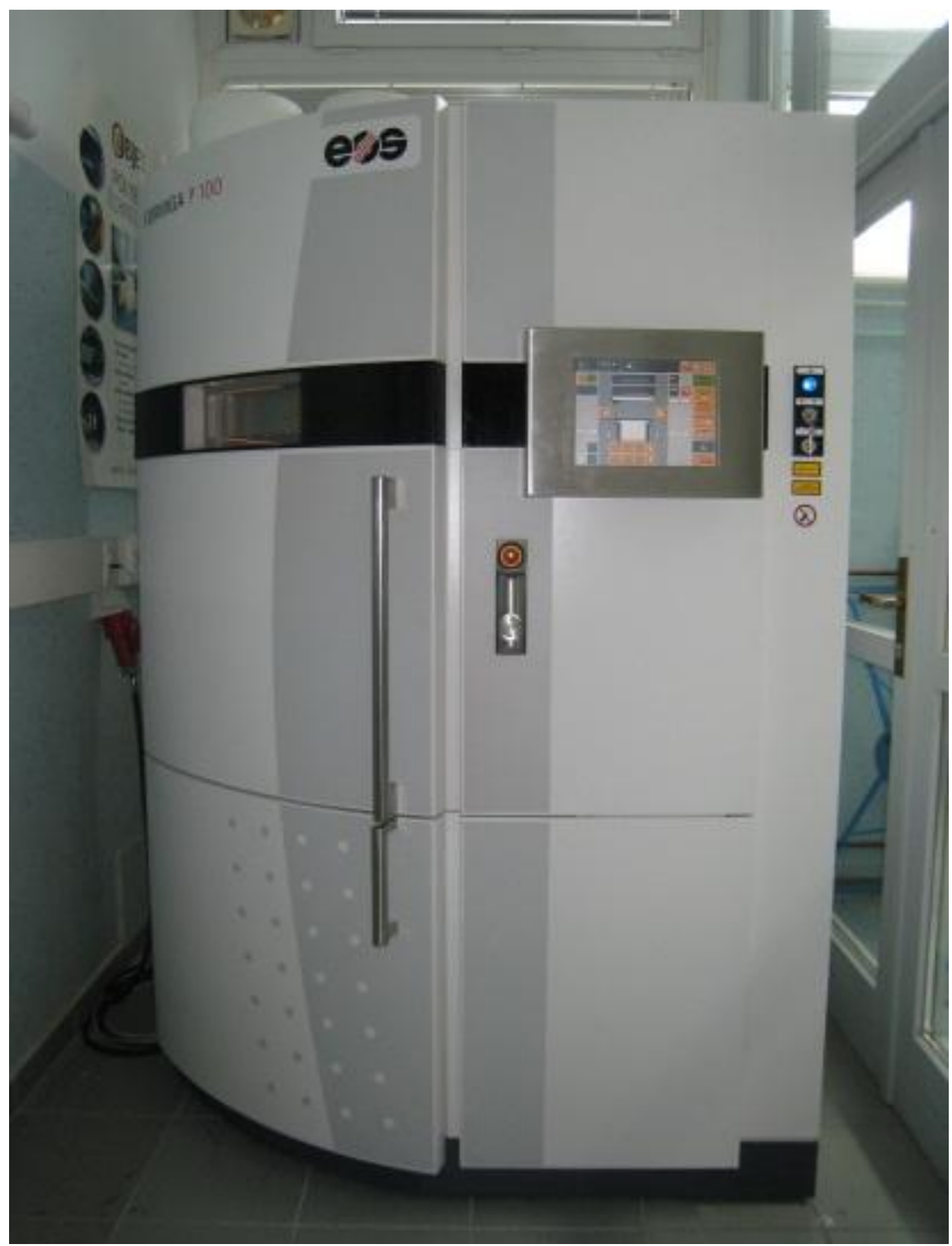

Fig. 5. The FORMIGA P 100

With a build envelope of $200 \times 250 \times 330 \mathrm{~mm}$, it produces plastic products from polyamide material within a few hours directly from 3D CAD data. The machine is ideally suited for the economic production of small series and 
Pogorevc, P.; Tasic, T. \& Brajlih, T.: Custom Shaped Caps for LPG Filling Points individualized products with complex geometry (Pahole et al., 2005). Because the polyamide material is very absorbent and the product surface is not very smooth, the colouring doesn't present any problem. Some stages of the laser-sintering process viewed by the FORMIGA P 100's software are shown on figure 6 .

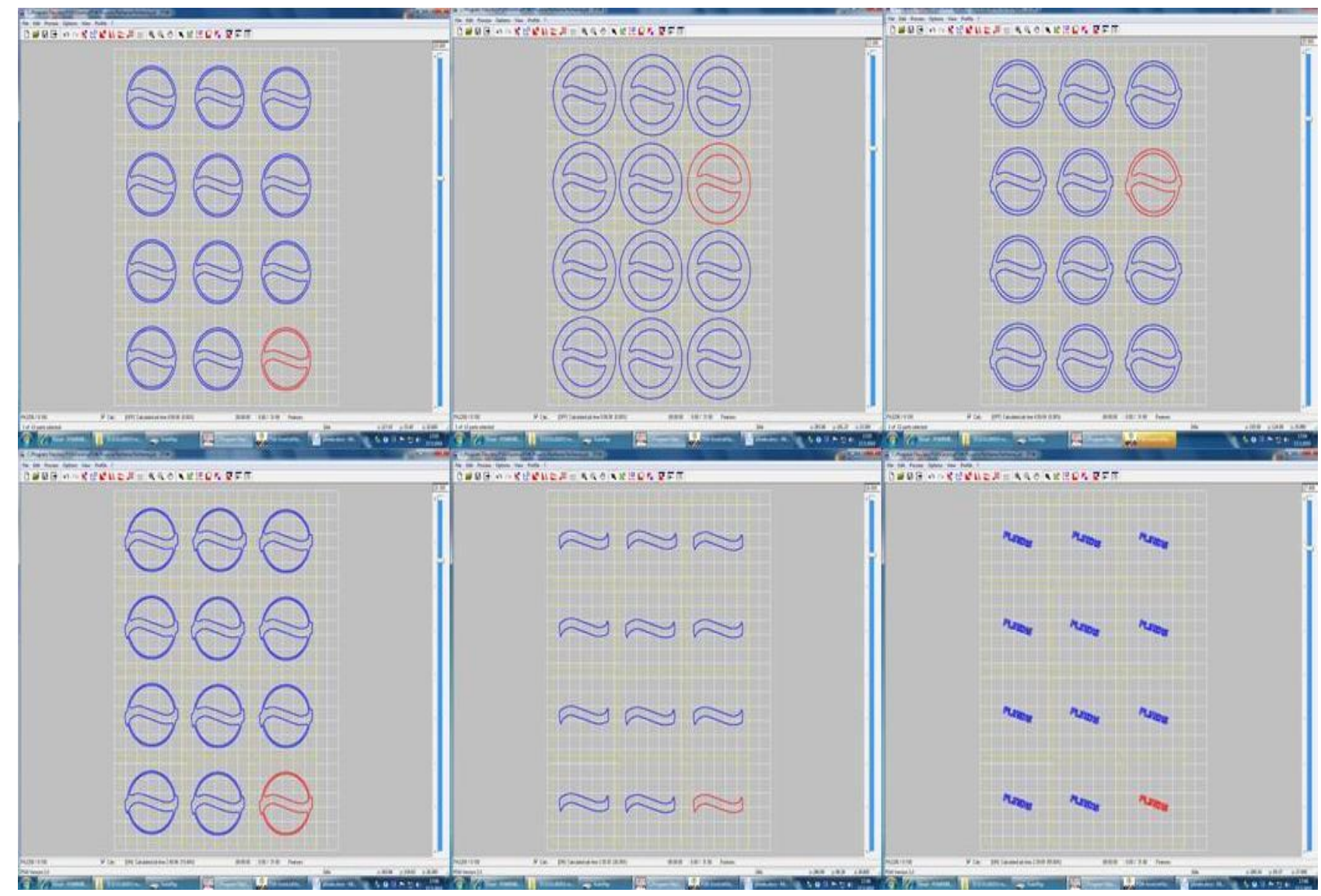

Fig. 6. Laser-sintering stages in FORMIGA P 100's software

As you can see, procedure stages are basically manufacturing product's crosssections. Figure 7 shows three different protection caps for LPG filling point. The left protection cap on is the standard one, produced by company Tomasetto Achille S.p.a.. It is made out of injection moulded black plastics.
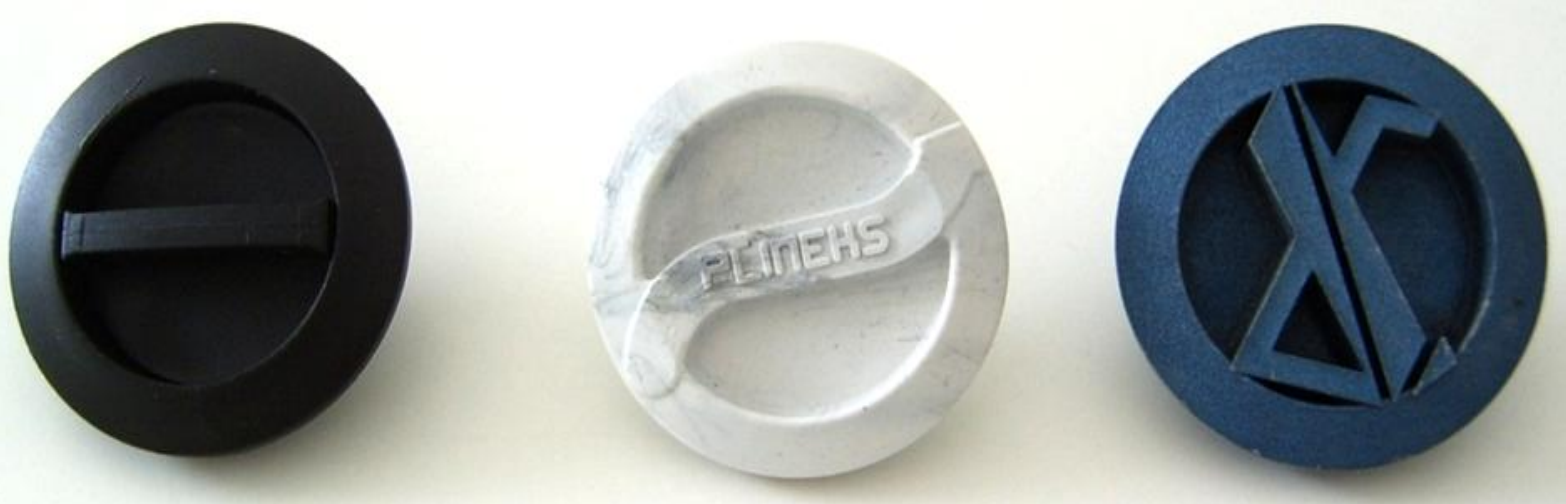

Fig. 7. Protection caps 
There are two separate plastic pieces, which are then stuck together (Figure 8.). The middle and the right protection caps of the Figure 7 are custom made out of polyamide material, manufactured by the laser-sintering method. The middle one has a part of the logo and firm name incorporated into the design (arrow and PLINEKS) and the right one has an acronym for doctor (dr.). As you can see on the right cap, very small gaps, sharp edges and $90^{\circ}$ angles between the planes are possible to manufacture with this method. Therefore there are numerous possibilities with the design and very small details can be incorporated in the finished product.
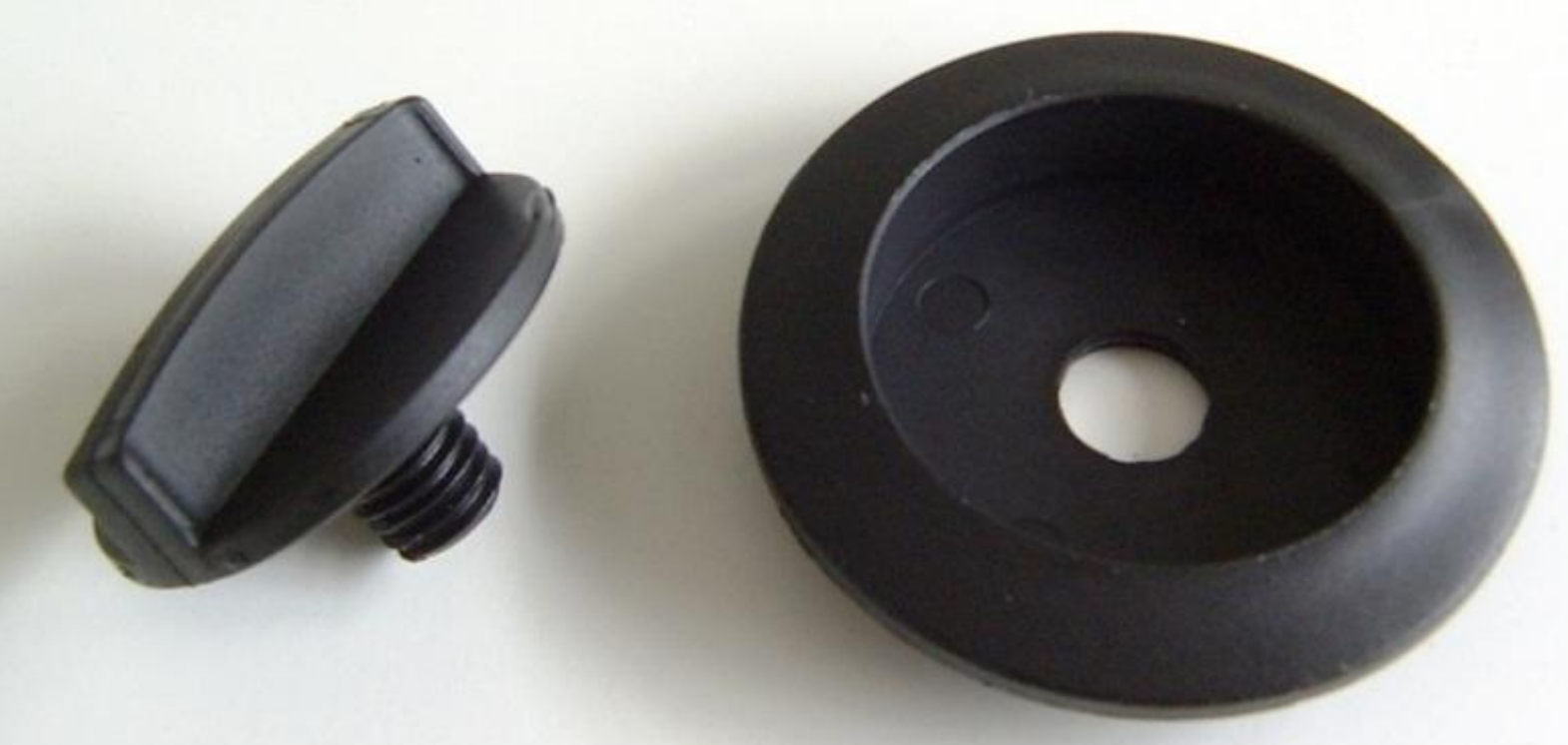

Fig. 8. Tomasetto Achille S.p.a. cap
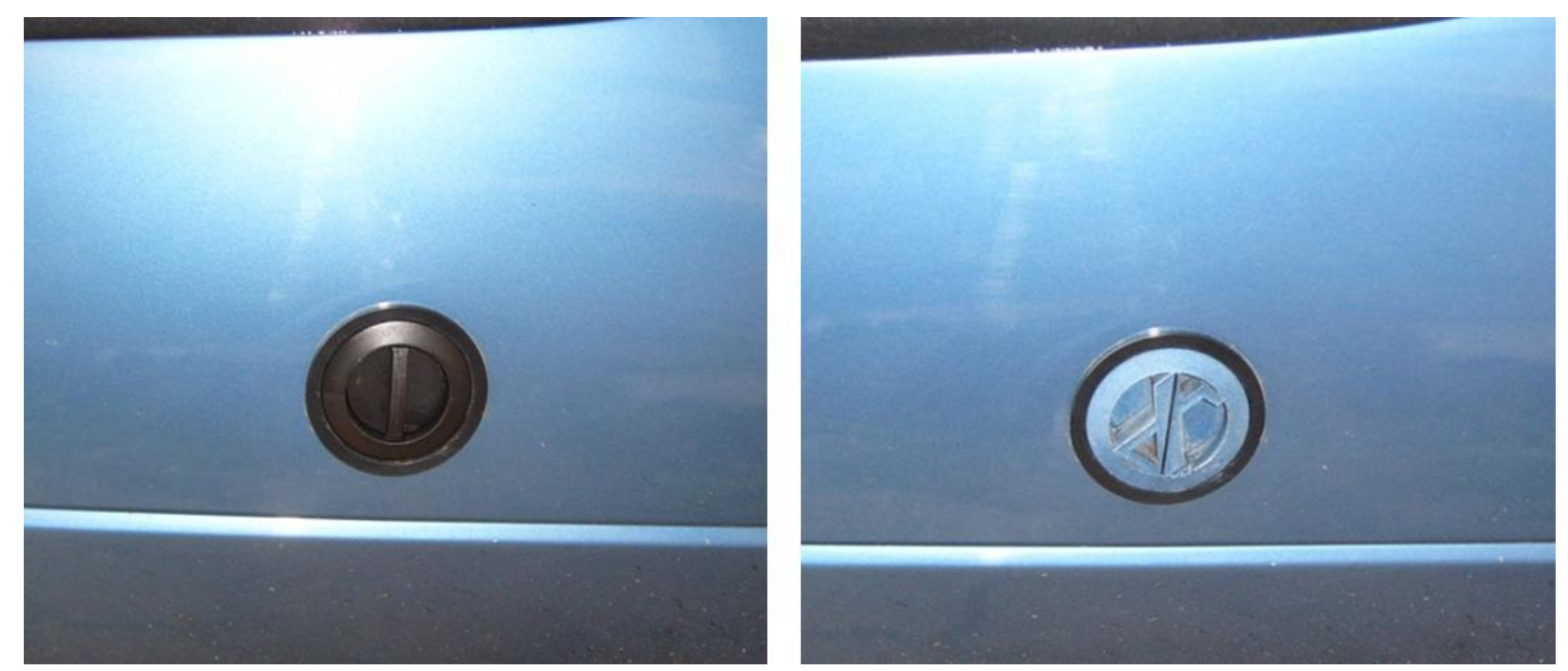

Fig. 9. Classic and custom made cap

Figure 9 shows a part of a rear bumper with the LPG filling point. On the left side there is a standard cap, while on the left the custom cap in the colour of the car can be seen. As you can see, coloured custom made cap looks better as a standard one. Because it is made as one piece, there is even less possibility for the dirt to come 
inside the filling point and therefore it assures even better protection. If the car's owner wants, also the plastic housing can be made in the same way.

\section{Conclusion}

So called aftermarket conversions of the petrol powered cars to run on LPG, are very popular all over the world. In comparison to the leading two transport fuels, there are two main advantages of LPG; lower emissions and lower price. Nowadays, car owners are very sensitive about their car appearance, so they are very annoyed if something does not look good on their cars. With the procedure of e-Manufacturing, 3D CAD software and laser-sintering, you can make much more acceptable protection caps with the reasonable costs in a very short time. Because of the material used, they can be easily painted into the colour of the car. Therefore, they are much less visible and look almost as a part of the car. The idea of custom protection cap was already presented to car owners, who decided for the aftermarket LPG conversion, and several custom caps protect filling points on their cars.

There are several other possibilities to incorporate e-Manufacturing in cars (Pahole et al., 2005) and also in the aftermarket LPG conversions; the changeover switch is one of them. Most of the cars have one or more plastic blends on their dashboards to cover up holes in them (rooms for additional switches). With the same procedure, changeover switch housing can be modified to fit in the desired hole. Therefore, it does not look like something extra, but as a part of the original dashboard.

\section{Acknowledgements}

Authors are sincerely thankful to Faculty of mechanical engineering, University of Maribor, for their support and cooperation.

\section{References}

Rosker, P. (2007). E-manufacturing with laser-sintering making mass customization real, The 1st DAAAM International Specialized Conference on Additive Technologies, 20th April 2007, Celje, Slovenia, Published by DAAAM International Vienna \& University of Maribor, Maribor

Pahole, I.; Drstvensek, I.; Veza, I. \& Balic, J. (2005). Use of rapid prototyping in renovation of old-timers, Annals of DAAAM for 2005 \& Proceedings of the 16th International DAAAM Symposium, 19-22nd October 2005, Opatija, Croatia, pp. 281-282, Published by DAAAM International Vienna, Vienna *** (2011) SHV GAS, Why LPG? - Brochure, http://whylpg.shvgas.com/, Accessed: 2011-05-10

*** (2011) http://www.landi.it, Accessed: 2011-05-15

*** (2011) http://www.3ddt.com.tr/pdf/formiga_p100_en.pdf, Accessed: 2011-05-15 